Alper Karakuş ${ }^{1}$, Berat Uğuz ${ }^{2}$

${ }^{1}$ Department of Cardiology, Besni State Hospital, Adıyaman, Turkey

${ }^{2}$ Department of Cardiology, Bursa City Hospital, Bursa, Turkey

\title{
AN EARLY ECHOCARDIOGRAPHIC PREDICTION FOR FUNCTIONAL MYOCARDIAL RECOVERY AFTER ST ELEVATION MYOCARDIAL INFARCTION
}

\begin{abstract}
Goal
Material and methods

Results

Conclusions

Keywords

For citation

Discrimination of the time course of functional recovery in early period following ST elevation myocardial infarction (STEMI) has prognostic importance. This study aims to establish the ability of the combined systolic-diastolic index (E/(Ea $\mathrm{x} \mathrm{Sa})$, for differentiating recoverable myocardium or persistent non-viability in subjects with STEMI.

77 patients with first acute STEMI were enrolled to the study. Serial transthoracic echocardiography (TTE) examinations were performed at the time of the admission (immediately after reperfusion), hospital discharge ( $5 \pm 1$ days) and control examination ( $30 \pm 2$ days). To assess the association between $\mathrm{E} /(\mathrm{Ea} \times \mathrm{Sa})$ index and myocardial recovery, two categories (Transient stunning and persistent non-viability) were defined on basis of improvement of left ventricle ejection fraction (LV EF) (Improvement was defined as an increase more than $10 \%$ in LV EF at day 30 compared to baseline).

55 patients $(71.4 \%)$ had improvement of LV EF and 24 patients $(28.6 \%)$ had no recovery of systolic function ( 30 days LV EF $48.78 \pm 6.1$ vs. $39.31 \pm 8.1 \%, \mathrm{p}=0.01)$. The $\mathrm{E} /(\mathrm{Ea} \times \mathrm{Sa})$ index were significantly higher in the "non-viability" than in stunning group on predischarge and 1 month $(1.61 \pm 0.64$ vs $1.25 \pm 0.43$, $\mathrm{p}=0.01$ and $1.33 \pm 0.25$ vs $1.14 \pm 0.21, \mathrm{p}=0.01$, respectively). The change in the $\mathrm{E} /(\mathrm{Ea} \times \mathrm{Sa})$ index in early period (within $5 \pm 1$ days) was higher in the stunning group (26\%) compared to non-viability group $(15 \%)(\mathrm{p}=0.033) . \mathrm{E} /(\mathrm{Ea} \times \mathrm{Sa})$ index was found to be a significant predictor of myocardial recovery in multivariable logistic regression (OR 0.91, 95\% CI 0.83-0.98, $\mathrm{p}=0.001$ ). Roc curve showed that the cutoff value of $\mathrm{E} /(\mathrm{Ea} \times \mathrm{Sa})$ index is 1.29 with $73 \%$ of sensitivity and $61 \%$ of specificity (AUC: 0.71 , $\mathrm{p}=0.01, \mathrm{CI}: 0.54-0.89)$.

Our findings suggest that $\mathrm{E} /(\mathrm{Ea} \times \mathrm{Sa})$ index is a strong predictor of functional recovery; the odds of recovery decreases as $\mathrm{E} /(\mathrm{Ea} \times \mathrm{Sa})$ index value increases.

Diastolic dysfunction; echocardiography; functional recovery; myocardial stunning; non-viability; ST elevation myocardial infarction

Alper Karakuş, Berat Uğuz. An early echocardiographic prediction for functional myocardial recovery after ST elevation myocardial infarction. Kardiologiia. 2021;61(1):66-71. [Russian: Айлпей Каракуш, Берат Угеузе. Раннее эхокардиографическое прогнозирование функционального восста-новления миокарда после инфаркта миокарда с подъемом сегмента ST. Кардиология. 2021;61(1):66-71].
\end{abstract}

Corresponding author

Alper Karakus. E-mail: alpkarakus06@gmail.com

\section{Introduction}

ST segment elevation myocardial infarction (STEMI) is the foremost cause of cardiovascular mortality and morbidity [1]. Primary percutaneous coronary intervention (PPCI) is the standard mechanical re-vascularization technique for patients with STEMI and aims to limit myocardial necrosis. Even if after a successful PPCI, re-perfused myocardium by the infarct-related coronary artery may remain akinetic due to transient myocardial stunning or persistent non-viability [2].

Stunning is a delayed response in myocardial recovery [3]. But the persistent non-viability is associated with adverse clinical outcomes and poor contractile function [4]. Over and above, patients who will not have a functional recovery will also be patients who are more likely to develop heart failure. So, predicting myocardium with potential for improvement in contractility and myocardium with irreversible dam- age can be useful to detect this group of patients at the early period of STEMI following PPCI.

The striking point, the initial studies limited the notion of myocardial stunning to systolic dysfunction. But the current studies support the presence of diastolic dysfunction (evidenced both by regional diastolic index [impaired left ventricular (LV) untwisting rate) and global diastolic index (increased E/e' ratio)] [5, 6].

A wide range of diagnostic techniques (Including dobutamine stress echocardiography, positron emulsion tomography scanning, radionuclide myocardial perfusion imaging, and cardiovascular magnetic resonance imaging) can determine the presence or absence of metabolic activity in that dysfunctional myocardial segment. However, these modalities are relatively costly and limited in availability.

The combined systolic-diastolic index, which is calculated as $\mathrm{E} /(\mathrm{Ea} \times \mathrm{Sa})$, is a reliable estimate parameter of increased LV 
filling pressure and decreased systolic functions, particularly in patients with regional wall motion abnormalities ( $E$ is the early diastolic mitral velocity, Ea is the early diastolic mitral annular velocity, and Sa is the systolic mitral annular velocity) [7-11].

We believe that myocardial recovery may be reflected to improvement of diastolic filling and systolic functions at early days after PPCI. So, in the present study we tested the ability of this combined systolic-diastolic index for differentiating recoverable myocardium or persistent non-viability.

\section{Material and methods}

\section{Study Protocol and Population}

The study was conducted in Bursa City Hospital (Turkey) between July 2020 and August 2020 and collaborated with Adıyaman Besni State Hospital (Turkey) for study design and data analysis. Eighty-nine patients with acute STEMI were enrolled to this cross-sectional study. Ethics Committee approved the study protocol (Registration number: 2020-5/4) and subjects who met study criteria consented informed.

\section{The study inclusion criteria}

- First acute STEMI based on the 2018 European Society of Cardiology (ESC) guideline on Fourth Universal Definition of Myocardial Infarction Guidelines [12].

- The onset of symptoms $<12$ hours.

\section{The study exclusion criteria}

- Patients with unsuccessful reperfusion (Thrombolysis in myocardial infarction (TIMI) score < III).

- Any complication during PPCI or requiring re-PCI during follow-up.

- Presence of pathological q/Q wave in admission electrocardiogram.

- History of previous coronary intervention.

- Use of loop diuretics during follow-up.

- Presence of previous MI, heart failure, cardiomyopathy, dysrhythmia (included atrial fibrillation) or any valvulopathy, which is more than mild.

\section{Angiographic Procedure}

The femoral or radial approach was used for coronary angiography and PPCI. The patients who needed thrombus aspiration or glycoprotein IIb-IIIa inhibitors infusion excluded from study. All patients received drug-eluting stents. TIMI III flow was achieved in all patients. All patients received medical treatment, including acetylsalicylic acid, P2Y12 inhibitor, beta-blockers, statins, aldosterone antagonists as appropriate, and angiotensin converting enzyme inhibitors or angiotensin receptors blockers according to 2017 ESC guideline on Acute Myocardial Infarction in Patients Presenting with ST-Segment Elevation (Management) Guidelines [13].

\section{Echocardiographic Evaluation}

Serial transthoracic echocardiography (TTE) examinations were performed by using GE Vivid S60 system with 2.5 MHz transducer (GE Vingmed Ultrasound AS, Horten, Norway).

- The admission TTE was done immediately after reperfusion (with seen more than 50\% resolution in ST segment elevation on ECG in 1 hour after PPCI).

- The second TTE was done at the time of hospital discharge ( $5 \pm 1$ days).

- The Third TTE was done at the time of the control examination ( $30 \pm 2$ days).

The LV ejection fraction (EF) was calculated by modified Simpson (biplane) method. LV myocardial recovery was defined as an increase more than $10 \%$ in LV EF between after PPCI and day 30 .

Peak early (E) and late (A) mitral entry velocities were recorded from the apical four-chamber view by pulsed-wave Doppler with the 5-mm sample volume. Tissue Doppler imaging recordings, $\mathrm{Sa}, \mathrm{Ea}$, and Aa values were recorded from the medial and lateral annulus in an apical four-chamber view and taken average of at least 3 cardiac cycles. $\mathrm{E} /(\mathrm{Ea} \times \mathrm{Sa})$ index value was calculated and presented as the arithmetic mean of the lateral and medial Ea and Sa velocities.

\section{Statistical Analysis}

The normality was analyzed by The Kolmogorov-Smirnov test. According to the normality pattern, continuous variables were presented as mean \pm standard deviation, or median and interquartile range. Student's $\mathrm{T}$ test was used when the assumption of normal distribution was met, and Mann-Whitney $\mathrm{U}$ test was used when normal distribution was not obtained. Categorical variables were compared by using the Chi-square test and the results were presented as percentages. One-way repeated ANOVA was used in terms of echocardiographic parameters for each group. Additionally, post-hoc test was applied to determine the groups that are significant. To assess the association between $\mathrm{E} /(\mathrm{Ea} \times \mathrm{Sa})$ index and myocardial recovery, two categories were defined according to whether there was a $10 \%$ improvement in EF. The effects of NT pro-BNP, creatinine, E/(EaxSa) index, high sensitive $\mathrm{C}$ reactive protein (Hs-CRP), door to balloon time, and age on myocardial recovery were determined with logistic regression analysis. The significant $P$-value was $<0.05$. SPSS 26.0 Statistical Package Software was used to perform all data analyses.

\section{Results}

Eighty-nine patients were evaluated for the study. Twelve patients with STEMI were excluded from initial study population (One patient dead, 5 patient had history of previous MI, 3 patients had history of previous PCI, 1 patient had missing data, 2 patients were not reached for follow up). The data of the remaining 77 patients were analyzed. 
Table 1. Baseline characteristics and laboratory findings of the study patients

\begin{tabular}{|c|c|c|c|}
\hline Variables & $\begin{array}{c}\text { Patients with } \\
\text { myocardial } \\
\text { stunning } \\
\text { (Group 1, } \\
\text { n=55, 71.4\%) }\end{array}$ & 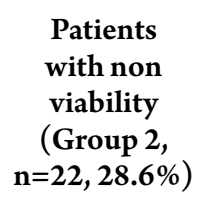 & p value \\
\hline Age (years) & $56.8 \pm 9.5$ & $60 \pm 13.1$ & 0.24 \\
\hline Sex $(n, \%)$ females & $10(18.1)$ & $5(22.7)$ & 0.53 \\
\hline Hypertension, n (\%) & $21(38.1)$ & $7(31.8)$ & 0.66 \\
\hline Dyslipidemia, n (\%) & $5(9)$ & $3(13.6)$ & 0.57 \\
\hline $\mathrm{DM}, \mathrm{n}(\%)$ & $20(36.3)$ & $5(22.7)$ & 0.22 \\
\hline Smoker, n (\%) & $27(49)$ & $13(59.1)$ & 0.47 \\
\hline $\begin{array}{l}\text { Body mass index } \\
\left(\mathrm{kg} / \mathrm{m}^{2}\right)\end{array}$ & $23.9 \pm 2.4$ & $24.7 \pm 3.5$ & 0.88 \\
\hline Glucose $(\mathrm{mg} / \mathrm{dl})$ & $174 \pm 43$ & $153 \pm 44$ & 0.10 \\
\hline $\begin{array}{l}\text { Creatinine }(\mathrm{mg} / \mathrm{dl}) \\
\text { Admission } \\
\text { Control }\end{array}$ & $\begin{array}{l}0.83 \pm 0.2 \\
0.93 \pm 0.2\end{array}$ & $\begin{array}{l}0.98 \pm 0.3 \\
1.08 \pm 0.3\end{array}$ & $\begin{array}{l}0.034 \\
0.018\end{array}$ \\
\hline Triglyceride $(\mathrm{mg} / \mathrm{dl})$ & $171 \pm 92$ & $143 \pm 87$ & 0.23 \\
\hline $\mathrm{LDL}(\mathrm{mg} / \mathrm{dl})$ & $118 \pm 36$ & $126 \pm 33$ & 0.36 \\
\hline $\mathrm{HDL}$ (mg/dl) & $37.9 \pm 18$ & $37.2 \pm 8$ & 0.87 \\
\hline $\mathrm{TSH}(\mu \mathrm{IU} / \mathrm{mL})$ & $1.73 \pm 1.3$ & $1.89 \pm 1.3$ & 0.64 \\
\hline $\mathrm{Na}(\mathrm{mmol} / \mathrm{L})$ & $137 \pm 3.6$ & $138 \pm 3$ & 0.37 \\
\hline $\mathrm{K}(\mathrm{mmol} / \mathrm{L})$ & $4.1 \pm 0.4$ & $4.0 \pm 0.5$ & 0.49 \\
\hline $\operatorname{AST}(\mathrm{U} / \mathrm{L})$ & $27 \pm 11$ & $31 \pm 6$ & 0.62 \\
\hline $\operatorname{ALT}(\mathrm{U} / \mathrm{L})$ & $24 \pm 7$ & $26 \pm 9$ & 0.42 \\
\hline $\begin{array}{l}\text { Hs-CRP }(\mathrm{nmol} / \mathrm{L}) \\
\text { Admission } \\
\text { Control }\end{array}$ & $\begin{array}{c}7.7 \pm 1.9 \\
3.45 \pm 0.9\end{array}$ & $\begin{array}{l}7.1 \pm 1.6 \\
5.2 \pm 0.6\end{array}$ & $\begin{array}{l}0.75 \\
0.15\end{array}$ \\
\hline $\begin{array}{l}\text { NTproBNP }(\mu \mathrm{mol} / \mathrm{L}) \\
\text { Admission } \\
\text { Control }\end{array}$ & $\begin{array}{l}677 \pm 95 \\
610 \pm 87\end{array}$ & $\begin{array}{c}678 \pm 67 \\
2235 \pm 564\end{array}$ & $\begin{array}{c}0.99 \\
0.026\end{array}$ \\
\hline Leukocyte $\left(10^{9} / \mathrm{L}\right)$ & $10.9 \pm 2.5$ & $11.6 \pm 3.8$ & 0.37 \\
\hline Hemoglobin $(\mathrm{g} / \mathrm{dl})$ & $13.6 \pm 1.7$ & $12.9 \pm 1.6$ & 0.51 \\
\hline Platelet $\left(10^{9} / \mathrm{L}\right)$ & $276 \pm 77$ & $259 \pm 72$ & 0.38 \\
\hline
\end{tabular}

DM: Diabetes mellitus, LDL: Light density lipoprotein,

HDL: High density lipoprotein, TSH: Thyroid-stimulating hormone, Na: Sodium, K: Potassium, AST: aspartate aminotransferase, ALT: alanine aminotransferase, HsCRP: High sensitive $\mathrm{C}$ reactive protein, Admission: 1 hour after primary percutaneous intervention, Control: $30 \pm 2$ days after admission.

Table 2. The angiographic characteristics of study groups

\begin{tabular}{l|c|c|c}
\multicolumn{1}{c}{ Variables } & $\begin{array}{c}\text { Patients with } \\
\text { myocardial } \\
\text { stunning } \\
\text { (Group 1, } \\
\text { N=55, 71.4\%) }\end{array}$ & $\begin{array}{c}\text { Patients with } \\
\text { Non viability } \\
\text { (Group 2, } \\
\text { N=22, 28.6\%) }\end{array}$ & p value \\
\hline Stent length (mm) & $28.5 \pm 11.8$ & $27.1 \pm 9.9$ & 0.63 \\
\hline Stent diameter (mm) & $2.93 \pm 0.3$ & $2.82 \pm 0.2$ & 0.13 \\
\hline MI territory & & & \\
Anterior MI, n (\%) & $23(41.8)$ & $9(41)$ & 0.12 \\
Non-anterior MI, n (\%) & $32(58.2)$ & $13(59)$ & 0.94 \\
\hline $\begin{array}{l}\text { Door-to-balloon } \\
\text { time (min) }\end{array}$ & $38.5 \pm 17$ & $41.5 \pm 16$ & 0.86 \\
\hline $\begin{array}{l}\text { IRA } \\
\text { LAD, n (\%) }\end{array}$ & $23(41.8)$ & $9(41)$ & 0.12 \\
Non-LAD, n (\%) & $32(58.2)$ & $13(59)$ & 0.94 \\
\hline
\end{tabular}

MI: Myocardial Infarction, IRA: Infarct related artery,

LAD: Left anterior descending, Min: Minute.
Study patients were categorized into two groups according to LV EF improvement compared to EF, which detected at first or second TTE examination at 1-month follow up. Patients with improvement in $\mathrm{EF}>10 \%$ during follow-up compared to the basal echocardiographic study who considered to have stunning (Group I or transient stunning group) were 55 (71.4\%) while the other patients without improvement of EF were 22 (28.6\%) (Group II or permanent non-viability group).

\section{Baseline and Follow-Up Characteristics}

Baseline demographic and clinical characteristics of study populations are presented in table 1. In brief, there was no found significant difference between both groups regarding the risk factors of coronary artery disease (including diabetes mellitus, hypertension, hyperlipidemia and smoking). Creatinine level was significantly higher in nonviability group than stunning group at baseline $(0.98 \pm 0.3$ vs $0.83 \pm 0.2 \mathrm{mg} / \mathrm{dl}, \mathrm{p}=0.034)$ and at 1 month $(1.08 \pm 0.3$ vs $0.93 \pm 0.2 \mathrm{mg} / \mathrm{dl}, \mathrm{p}=0.018$ ). NT pro-BNP was significantly higher in non-viability group compared to stunning group at follow up.

\section{Angiographic Characteristics}

No significant difference was observed between the groups regarding stent length and diameter, myocardial infarction territory and door to balloon time. The angiographic features were summarized in table 2.

\section{Echocardiographic Characteristics}

Regarding the baseline echocardiographic characteristics, peak E (Admission), E/A ratio (Admission), and E/Ea ratio (Admission and 1 month) were significantly higher in the non-viability group. The results are shown in table 3.

\section{The Combined Systolic-Diastolic Index}

The $\mathrm{E} /(\mathrm{Ea} \times \mathrm{Sa})$ index value in both groups is presented in table 3. The $\mathrm{E} /(\mathrm{Ea} \times \mathrm{Sa})$ index (Predischarge and 1-month values) were significantly higher in the non-viability than in stunning group. On the other hand, in the stunning group, the index before discharge from the hospital decreased by $26 \%$ compared to the early period index after PPCI (Admission), while this decrease was observed by $15 \%$ in the nonviability group. The percentage of change of $\mathrm{E} /(\mathrm{Ea} \times \mathrm{Sa})$ index at hospitalization period ( $5 \pm 1$ days) was compared between both groups and found statistically significant $(\mathrm{p}=0.033)$.

\section{Identification of the Predictors for Myocardial Recovery}

Multivariable logistic regression analysis to assess factors predictive of myocardial recovery included NT-proBNP, creatinine, baseline $\mathrm{E} /(\mathrm{Ea} \times \mathrm{Sa})$ index, Hs-CRP, door to balloon 
Table 3. Comparison of echocardiographic parameters of the study patients

\begin{tabular}{|c|c|c|c|}
\hline Variables & $\begin{array}{c}\text { Patients with } \\
\text { myocardial } \\
\text { stunning } \\
\text { (Group 1, } \\
\text { n=55, 71.4\%) }\end{array}$ & $\begin{array}{c}\text { Patients with } \\
\text { non viability } \\
\text { (Group 2, } \\
\mathrm{n}=22,28.6 \%)\end{array}$ & $\mathrm{p}^{*}$ value \\
\hline \multicolumn{4}{|l|}{ LVEF (\%) } \\
\hline Admission & $44.50 \pm 6.6$ & $43.1 \pm 0.4$ & 0.45 \\
\hline Predischarge & $44.58 \pm 6.8$ & $42.95 \pm 9.3$ & 0.40 \\
\hline Control & $48.78 \pm 6.1$ & $39.31 \pm 8.1$ & 0.01 \\
\hline $\mathrm{p}^{* *}$ value & $0.02^{\mathrm{a}, \mathrm{b}}$ & $0.03^{\mathrm{a}}$ & - \\
\hline \multicolumn{4}{|c|}{ Mitral E velocity\# } \\
\hline Admission & $72.39 \pm 21.32$ & $85.86 \pm 13.76$ & 0.01 \\
\hline Predischarge & $87.58 \pm 17.84$ & $90.14 \pm 18.55$ & 0.33 \\
\hline Control & $76.30 \pm 16.38$ & $80.04 \pm 11.83$ & 0.27 \\
\hline $\mathrm{p}^{* *}$ value & $0.01^{b, c}$ & $0.02^{\mathrm{b}}$ & - \\
\hline \multicolumn{4}{|c|}{ Mitral A velocity\# } \\
\hline Admission & $82.80 \pm 15.62$ & $84.54 \pm 21.66$ & 0.69 \\
\hline Predischarge & $83.53 \pm 16.50$ & $80.86 \pm 20.70$ & 0.55 \\
\hline Control & $82.60 \pm 16.41$ & $82.36 \pm 20.33$ & 0.95 \\
\hline $\mathrm{p}^{* *}$ value & 0.75 & 0.30 & - \\
\hline \multicolumn{4}{|l|}{ Mitral E/A } \\
\hline Admission & $0.90 \pm 0.35$ & $1.07 \pm 0.27$ & 0.04 \\
\hline Predischarge & $1.03 \pm 0.37$ & $1.08 \pm 0.35$ & 0.56 \\
\hline Control & $0.97 \pm 0.34$ & $1.04 \pm 0.41$ & 0.43 \\
\hline $\mathrm{p}^{* *}$ value & $0.04^{c}$ & 0.28 & - \\
\hline \multicolumn{4}{|c|}{ Mitral Ea velocity\# } \\
\hline Admission & $9.20 \pm 2.1$ & $9.07 \pm 1.5$ & 0.79 \\
\hline Predischarge & $9.76 \pm 2.3$ & $9.76 \pm 2.3$ & 0.31 \\
\hline Control & $10.7 \pm 1.9$ & $10.7 \pm 1.9$ & 0.64 \\
\hline $\mathrm{p}^{* *}$ value & $0.01^{\mathrm{a}, \mathrm{b}}$ & $0.02^{\mathrm{a}, \mathrm{b}}$ & - \\
\hline \multicolumn{4}{|c|}{ Mitral Aa velocity\# } \\
\hline Admission & $11.1 \pm 1.7$ & $11.5 \pm 2.1$ & 0.34 \\
\hline Predischarge & $11.5 \pm 2.1$ & $10.6 \pm 2.1$ & 0.11 \\
\hline Control & $12.0 \pm 1.7$ & $11.5 \pm 2.1$ & 0.24 \\
\hline $\mathrm{p}^{* *}$ value & 0.13 & 0.29 & - \\
\hline \multicolumn{4}{|c|}{ Mitral Sa velocity\# } \\
\hline Admission & $10.2 \pm 1.8$ & $10.5 \pm 2.1$ & 0.48 \\
\hline Predischarge & $10.4 \pm 2.0$ & $10.2 \pm 2.2$ & 0.72 \\
\hline Control & $10.9 \pm 1.7$ & $11.0 \pm 1.9$ & 0.98 \\
\hline $\mathrm{p}^{* *}$ value & $0.04^{\mathrm{a}}$ & $0.03^{\mathrm{b}}$ & - \\
\hline \multicolumn{4}{|l|}{$\mathrm{LVE} / \mathrm{Ea}$} \\
\hline Admission & $7.9 \pm 1.8$ & $9.8 \pm 2.6$ & 0.01 \\
\hline Predischarge & $8.8 \pm 1.7$ & $9.2 \pm 2.3$ & 0.46 \\
\hline Control & $8.1 \pm 1.8$ & $9.1 \pm 2.5$ & 0.04 \\
\hline $\mathrm{p}^{* *}$ value & $0.03^{b, c}$ & 0.10 & - \\
\hline \multicolumn{4}{|c|}{$\mathrm{E} /(\mathrm{Ea} \times \mathrm{Sa})$ index } \\
\hline Admission & $1.83 \pm 0.63$ & $2.02 \pm 0.92$ & 0.30 \\
\hline Predischarge & $1.25 \pm 0.43$ & $1.61 \pm 0.64$ & 0.01 \\
\hline Control & $1.14 \pm 0.21$ & $1.33 \pm 0.25$ & 0.01 \\
\hline $\mathrm{p}^{* *}$ value & $0.01^{\mathrm{a}, \mathrm{c}}$ & $0.01^{\mathrm{a}, \mathrm{c}}$ & - \\
\hline
\end{tabular}

LV; Left ventricle, EF; ejection fraction, Admission: 1 hour after primary percutaneous intervention, Predischarge: $5 \pm 1$ days after admission. Control: $30 \pm 2$ days after admission. \#; $(\mathrm{cm} / \mathrm{s}),{ }^{*}$; $\mathrm{p}$ values; Independent Samples-T Test, ${ }^{* * *}$; $\mathrm{p}$ values; repeated measures ANOVA. a: $\mathrm{p}<0.05$ : Admission vs. Control; $\mathrm{b}$ : $\mathrm{p}<0.05$ : Predischarge vs. Control; c: $\mathrm{p}<0.05$ : Admission vs. Predischarge.
Figure 1. Roc curve showed that the cutoff value of E/(EaxSa) index is 1.29 with $73 \%$ of sensitivity and $61 \%$ of specificity

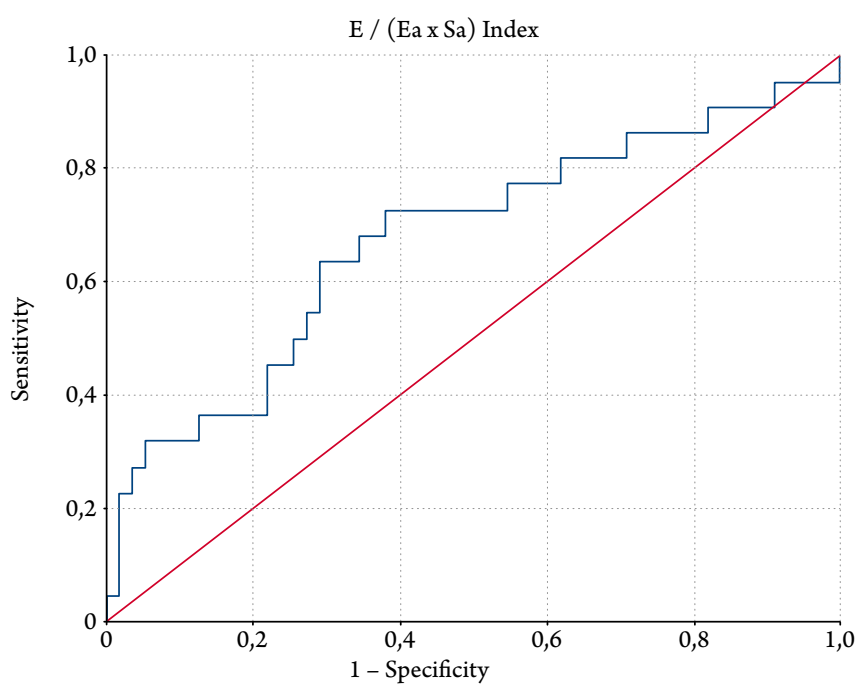

AUC: $0.71, \mathrm{p}=0.01, \mathrm{CI}: 0.54-0.89$

time, and age showed that $\mathrm{E} /(\mathrm{Ea} \times \mathrm{Sa})$ index was the only predictive factor for myocardial recovery (OR: $0.91,95 \% \mathrm{CI}$ (0.83-0.98), $\mathrm{P}=0.001$ ) (tab. 4). Roc curve showed that the cutoff value of $\mathrm{E} /(\mathrm{Ea} \times \mathrm{Sa})$ index is 1.29 with $73 \%$ of sensitivity and $61 \%$ of specificity (AUC: $0.71, \mathrm{p}=0.01, \mathrm{CI}$ : $0.54-$ 0.89) (fig. 1).

\section{Discussion}

Our findings suggest that persistent LV dysfunction and transient myocardial stunning can be distinguished in the early period after STEMI. Furthermore, E/ (Ea×Sa) index value to be a strong predictor of functional recovery; the odds of full recovery decreases as $\mathrm{E} /(\mathrm{Ea} \times \mathrm{Sa})$ index value increases.

Myocardial stunning is typically defined as transient myocardial dysfunction in areas of restored coronary perfusion after STEMI [3]. Acute occlusion of a coronary artery rapidly impairs contractile function and may result in myocardial necrosis depending on the occlusion duration [14-16]. Previous research demonstrated the diastolic dysfunction of LV during myocardial stunning.

Table 4. Identification of the predictors

for myocardial recovery with multiple regression analysis

\begin{tabular}{lccc}
\multicolumn{1}{c}{ Variables } & OR $(\mathbf{C I}, \mathbf{9 5} \%)$ & p value \\
\hline Age & $1.03(0.99-1.08)$ & 0.08 \\
\hline E/(Ea x Sa) index & $0.91(0.83-0.98)$ & 0.001 \\
\hline Creatinine & $1.14(1.06-1.23)$ & 0.32 \\
\hline NT-proBNP & $1.01(0.94-1.07)$ & 0.70 \\
\hline Hs-CRP & $1.11(0.97-1.19)$ & 0.09 \\
\hline Door to balloon time & $1.05(0.97-1.11)$ & 0.65
\end{tabular}

Hs-CRP: High sensitive $C$ reactive protein,

NT-proBNP: N-terminal pro-b-type natriuretic peptide. 
Besides, Mornos C. et al. demonstrated that E/(EaxSa) index is useful and reliable parameter to assess the LV filling pressure, particularly in patients with regional wall motion abnormalities [7]. And also, it is more logical to evaluate diastolic (relaxation) and systolic (contraction) functions together as part of the ongoing cycle. So, in this present study, we assessed the early predictive value of $\mathrm{E} /(\mathrm{Ea} \times \mathrm{Sa})$ index for improvements in LV functions after STEMI.

The substantial recovery of systolic function that occurred within 30 days after MI was the endpoint of our study; $71.4 \%$ of patients had improvement of LV EF and $28.6 \%$ had no recovery of systolic function ( $48.78 \pm 6.1$ vs. $39.31 \pm 8.1 \%, p=0.01$ ). And, there was no statistically significant difference in term of LV EF in both groups before discharge from the hospital ( $44.58 \pm 6.8$ vs. $42.95 \pm 9.3 \%$, $\mathrm{p}=0.40$ ). This extent of systolic recovery in our study population appears to be consistent with that reported in most previous studies $[17,18]$.

Patients who did not have myocardial recovery had significantly higher $\mathrm{E} /(\mathrm{Ea} \times \mathrm{Sa})$ index value pattern during entire follow up compared to patients who had improvement of $\mathrm{LV}$ $E F$. The one of the most striking findings of our study is that there was, on average, decrease of $26 \%$ in the $\mathrm{E} /(\mathrm{E} \times \mathrm{Sa})$ in dex value compared to the initial TTE measurement in transient stunning group (within 5 days). This dramatic change was seen, on average, of $15 \%$ in non-viability group. Likewise, we did observe that $\mathrm{E} /(\mathrm{Ea} \times \mathrm{Sa})$ index was higher level in non-viability group ( $1.33 \pm 0.25$ vs. $1.14 \pm 0.21, \mathrm{p}=0.01)$, similar to the predischarge measures. The literature suggests that most systolic myocardial recovery occurs within the first 2 weeks after MI, but the available data do not allow further discrimination of the time course of recovery [19-21]. So, our findings may have important implications about the prognostic value of clinical assessment of LV function early in the course of STEMI.

At 1 month, we found that patients in the stunning group had a significantly better LV diastolic function, reflecting in a lower ratio of $\mathrm{E} / \mathrm{Ea}$. We found that other conventional echocardiographic measurements including mitral E velocity, mitral E/A ratio had shown differences between groups. But they were less linked to improvement in ventricular function. Our analysis demonstrated that the diagnostic accuracy of the $\mathrm{E} /(\mathrm{Ea} \times \mathrm{Sa})$ index in predicting functional myocardial recovery after PPCI is more sensitive and specific than that of traditional diastolic parameters including $\mathrm{E} / \mathrm{Ea}$ ratio and Sa wave (the E / $(\mathrm{Ea} \times \mathrm{Sa})$ index $=73 \%$ of sensitivity and $61 \%$ of specificity (AUC: $0.71, \mathrm{p}=0.01, \mathrm{CI}: 0.54-0.89$ ), the $\mathrm{E} / \mathrm{Ea}$ ratio $=64 \%$ of sensitivity and $41 \%$ of specificity $(\mathrm{AUC}=0.67, \mathrm{p}=0.03, \mathrm{CI}: 0.61-0.74)$, Sa wave $=53 \%$ of sensitivity and $56 \%$ of specificity $(\mathrm{AUC}=0.65, \mathrm{p}=0.03$,
CI: $0.57-0.73)$ ). Similar results were demonstrated by Lam W. which evaluating LV suction functions in the dobutamine stress echocardiography -based study [5] In contrast, Faustino $\mathrm{M}$. et al. reported that $\mathrm{E} / \mathrm{Ea}$ ratio was an independent predictor of myocardial recovery in patients with MI [6]. Consequently, our findings suggest that the severity of the $\mathrm{E} /(\mathrm{Ea} \times \mathrm{Sa})$ index and its ratio of change in early period was superior to other echocardiographic parameters in predicting recovery of LV function at 1 month after STEMI and PPCI. The patient with lower decrease of initial $\mathrm{E} /(\mathrm{Ea} \times \mathrm{Sa}$ ) index (within 5 days) and the patients with predischarge $\mathrm{E} /(\mathrm{Ea} \times \mathrm{Sa})$ index $>1.29$ presented with poor functional recovery after 1 month following STEMI.

Additionally, we did not find differences in the initial examination of any inflammatory response (increased white blood cell counts and high level of Hs-CRP and plasma glucose) related to functional recovery in both groups. It is not surprising that control NT-proBNP level compared to admission was higher in non-viability group. The increased NT-proBNP may play a role in why improvement of EF was lesser in this group. Likewise, creatinine level was higher in non-viability group than transient stunning group. But it may be arguable that creatinine level at admission was also significantly higher in this group. Nevertheless, creatinine levels were not found to be associated with $\mathrm{E} /(\mathrm{Ea} \times \mathrm{Sa})$ index and improvement of LV EF. So, we believe that these data did not reflect any selection bias against functional recovery.

This study has some strengths and limitations that are worth noting. One of strengths is that contrary to other imaging modalities, no contrast agent or inotropic agent was used. Another one is that predicting functional recovery occurs relatively early. And also, we believe that our results can be used for the risk stratification of the patient following STEMI and PPCI. First limitation, the all differences between stunning and non-viability groups were assessed by echocardiography and were limited by 30 days. Thus, no other imaging modality was used to reveal the ultimate extent of functional recovery. Second, PPCI based successful reperfusion therapy was mandated by the study protocol. Therefore, the data can only be interpreted for this patient group. Third, the power of study is under limitation of relatively small sample size. On the other hand, our results could be pioneer for larger studies.

In conclusion, our findings suggest that the combined systolic-diastolic $([\mathrm{E} /(\mathrm{Ea} \times \mathrm{Sa})])$ index, is related to recovery of ventricular function after STEMI and could be a more important predictor of functional recovery than other early echocardiographic measures. And, using this index in early period for prognostic assessment may be the ideal. 


\section{Informed consent}

The study protocol was approved with registration number of $2020-5 / 4$ by the Bursa City Hospital ethics committee.

\section{Acknowledgement}

We would like to thank Prof.Dr. Mustafa KILIÇKAP

(Ankara University, School of Medicine, Cardiolo- gy Department, Ankara, Turkey) for supervision, Assoc. Prof. Dr. Emrah CINKARA (Gaziantep University, Turkey) for language control and Dr. Nurbanu BURSA (Hacettepe University, Turkey) for support.

\section{No conflict of interest is reported.}

The article was received on $28 / 11 / 2020$

\section{REFERENCES}

1. Vogel B, Claessen BE, Arnold SV, Chan D, Cohen DJ, Giannitsis $\mathrm{E}$ et al. ST-segment elevation myocardial infarction. Nature Reviews Disease Primers. 2019;5(1):39. DOI: 10.1038/s41572-0190090-3

2. Guaricci AI, Bulzis G, Pontone G, Scicchitano P, Carbonara R, Rabbat $\mathrm{M}$ et al. Current interpretation of myocardial stunning. Trends in Cardiovascular Medicine. 2018;28(4):263-71. DOI: 10.1016/j. tcm.2017.11.005

3. Braunwald E, Kloner RA. The stunned myocardium: prolonged, postischemic ventricular dysfunction. Circulation. 1982;66(6):1146-9. DOI: 10.1161/01.CIR.66.6.1146

4. Yap J, Lim FY, Gao F, Wang SZ, Low SCS, Le TT et al. Effect of Myocardial Viability Assessed by Cardiac Magnetic Resonance on Survival in Patients With Severe Left Ventricular Dysfunction. Circulation Reports. 2020;2(6):306-13. DOI: 10.1253/circrep.CR19-0126

5. Lam W, Leano R, Haluska B, Marwick TH. Effects of myocardial ischaemia on left ventricular untwist and filling pressure. Heart. 2011;97(9):757-61. DOI: 10.1136/hrt.2010.201699

6. Faustino M, Baptista SB, Freitas A, Monteiro C, Leal P, Nédio M et al. The Index of Microcirculatory Resistance as a Predictor of Echocardiographic Left Ventricular Performance Recovery in Patients With ST-Elevation Acute Myocardial Infarction Undergoing Successful Primary Angioplasty. Journal of Interventional Cardiology. 2016;29(2):137-45. DOI: 10.1111/joic. 12278

7. Mornos C, Cozma D, Rusinaru D, Ionac A, Maximov D, Petrescu L et al. A novel index combining diastolic and systolic Tissue Doppler parameters for the non-invasive assessment of left ventricular end-diastolic pressure. International Journal of Cardiology. 2009; 136(2):1209. DOI: $10.1016 /$ j.ijcard.2008.04.029

8. Mornoş C, Petrescu L, Ionac A, Cozma D. The prognostic value of a new tissue Doppler parameter in patients with heart failure. The International Journal of Cardiovascular Imaging. 2014;30(1):4755. DOI: $10.1007 / \mathrm{s} 10554-013-0294-7$

9. Ari H, Ari S, Sarigül OY, Coşar S, Doğanay K, Emlek N et al. A Novel Index Combining Diastolic and Systolic Tissue Doppler Parameters for Prediction of Atrial Fibrillation Recurrence. Echocardiography. 2016;33(7):1009-15. DOI: 10.1111/echo.13212

10. Camci S, Ari S, Karakus A, Ari H, Taner T. The predictive value of the combined systolic-diastolic index for atrial fibrillation after coronary artery bypass surgery. Echocardiography. 2020;37(8):1177-83. DOI: $10.1111 /$ echo.14806

11. Ari S, Ari H, Tütüncü A, Çamci S, Vatansever Ağca F, Melek M. A novel index combining diastolic and systolic tissue Doppler parameters for predicting cardiac resynchronization therapy response. Echocardiography. 2020;37(8):1184-91. DOI: 10.1111/echo.14797

12. Williams B, Mancia G, Spiering W, Agabiti Rosei E, Azizi M, Burnier $M$ et al. 2018 ESC/ESH Guidelines for the management of arterial hy- pertension. European Heart Journal. 2018;39(33):3021-104. DOI: 10.1093/eurheartj/ehy339

13. Ibanez B, James S, Agewall S, Antunes MJ, Bucciarelli-Ducci C, Bueno $\mathrm{H}$ et al. 2017 ESC Guidelines for the management of acute myocardial infarction in patients presenting with ST-segment elevation: The Task Force for the management of acute myocardial infarction in patients presenting with ST-segment elevation of the European Society of Cardiology (ESC). European Heart Journal. 2018;39(2):11977. DOI: $10.1093 /$ eurheartj/ehx393

14. Tatli E, Aktoz M, Altun A. A Patient With Unstable Angina and Without Abnormal Electrocardiographic Findings and Total Occlusion of the Left Anterior Descending Coronary Artery. Trakya Universitesi Tip Fakultesi Dergisi. 2010;27(1):83-5. [Av. at: https://www.researchgate.net/publication/288813603_A_Patient_With_Unstable Angina_and_Without_Abnormal_Electrocardiographic_Findings_ and_Total_Occlusion_of_the_Left_Anterior_Descending_Coronary_Artery]

15. Cokkinos DV. Myocardial Stunning. [P. 171-184. DOI: 10.1007/978 3-319-98186-4_9]. In: Myocardial Preservation. [ISBN: 978-3-31998185-7] Cokkinos DV, editor -Cham: Springer International Publishing;2019.

16. Neri M, Riezzo I, Pascale N, Pomara C, Turillazzi E. Ischemia/Reperfusion Injury following Acute Myocardial Infarction: A Critical Issue for Clinicians and Forensic Pathologists. Mediators of Inflammation. 2017;2017:7018393. DOI: 10.1155/2017/7018393

17. Solomon SD, Glynn RJ, Greaves S, Ajani U, Rouleau J-L, Menapace $\mathrm{F}$ et al. Recovery of Ventricular Function after Myocardial Infarction in the Reperfusion Era: The Healing and Early Afterload Reducing Therapy Study. Annals of Internal Medicine. 2001;134(6):451-8. DOI: 10.7326/0003-4819-134-6-200103200-00009

18. Rifqi S, Sungkar S, Sobirin MA, Uddin I, Furuse Y, Nugroho MA et al. Early recovery of left ventricular function after revascularization of coronary artery disease detected by myocardial strain. Biomedical Research. 2017;28(4):1487-92. [Av. at: https://www.semanticscholar. $\mathrm{org} /$ paper/Early-recovery-of-left-ventricular-function-after-Rifqi-Sun gkar/77556515261b781086c9c8240a89d2746e946ff5]

19. Bhatt AS, Ambrosy AP, Velazquez EJ. Adverse Remodeling and Reverse Remodeling After Myocardial Infarction. Current Cardiology Reports. 2017;19(8):71. DOI: 10.1007/s11886-017-0876-4

20. Lesizza P, Prosdocimo G, Martinelli V, Sinagra G, Zacchigna S, Giacca M. Single-Dose Intracardiac Injection of Pro-Regenerative MicroRNAs Improves Cardiac Function After Myocardial Infarction. Circulation Research. 2017;120(8):1298-304. DOI: 10.1161/CIRCRESAHA.116.309589

21. Daubert MA, White JA, Al-Khalidi HR, Velazquez EJ, Rao SV, Crowley AL et al. Cardiac remodeling after large ST-elevation myocardial infarction in the current therapeutic era. American Heart Journal. 2020;223:87-97. DOI: 10.1016/j.ahj.2020.02.017 